\title{
Margaret McCartney: When a crisis is the predictable outcome of poor policy making
}

\author{
Margaret McCartney general practitioner
}

Glasgow

When is a crisis not a crisis? The "crisis" may be felt differently in the UK's four NHSs, but these services are being pushed beyond reasonable capacity. I've little doubt that the coping mechanisms - corridor care, ambulance stacking, and a month's worth of cancelled operations and outpatient appointments-are harmful. And these will contribute to burnout, sick leave, resignation, early retirement, and the cycle of even more rota gaps.

This is not a sudden explosive "crisis" but the predictable, and predicted, result of multifactorial choices over long periods that have made a mockery of evidence based decision making. This is winter: it's a foreseeable annual event.

Yes, the NHS needs more money. But that money's wasted if it's spent on initiatives that don't work and are driven by party politics, not patients. And it's been spent on such initiatives repeatedly and avoidably. England has had the internal market and vast monetary waste from administering the legal framework, ${ }^{1}$ such that Virgin sued the NHS in 2017 in a dispute over tendering. ${ }^{2}$ This money should have been spent on direct patient care.

This is not a sudden explosive "crisis" but the predictable, and predicted, result of multifactorial choices over long periods

In Scotland a quarter of delayed discharges have been due to a lack of residential care beds. ${ }^{3}$ England has $43 \%$ fewer general and acute hospital beds than 30 years ago and fewer beds per head of population than any comparable country. ${ }^{4}$ People can't get into hospital, but neither can they safely leave.

In 2013, management consultancies were telling us that technology would save us, ${ }^{5}$ when it couldn't; and the government said that telehealth could save the NHS $£ 1.2$ bn a year, ${ }^{6}$ before a randomised controlled trial found that it wasn't cost effective. ${ }^{7}$ This was all money that could have paid for beds, hospital nursing, and community care.

Austerity has meant English councils cutting adult social care by $11 \%$ in real terms. ${ }^{8}$ The privatised, opaque process of carrying out medical assessments of eligibility for benefits has had a "substantial disadvantage" for the people it should have helped, ${ }^{9}$ while being associated with worsening mental health. ${ }^{10}$ This is avoidable harm done to patients and picked up by primary care, all while the provider turns a profit.

The origins of the current winter "crisis" have their roots in multiple places, all accumulating harm. Yet several campaigns aim to change behaviour by advising alternatives to visiting a hospital or GP.

These campaigns are untested and may not work—but they may harm. Patients, induced into guilt about "taking up resources," may delay consultations and incur avoidable, expensive complications. Shifting problems we've failed to tackle onto the shoulders of ill people is unfair. This is a systemic problem that needs systemic change. If we can't get the essentials of the NHS right we're failing everyone, including the staff.

We've had our fill of short termism and party political policy making. We need to plan for the long term, seek cross party agreements, prioritise the basics, and have an "evidence desk" using expertise and systematic reviews, over which we can debate policy, disallow conflicts of interest, and stop wasteful nonsense in its tracks.

\section{Competing interests: See www.bmj.com/about-bmj/freelance-} contributors/margaret-mccartney.

Provenance and peer review: Commissioned; not externally peer reviewed.

Follow Margaret on Twitter, @mgtmccartney

\footnotetext{
Full Fact. How much is the NHS market costing? 31 March 2014. https://fullfact.org/health/ how-much-nhs-market-system-costing/.

2 Taylor K. Virgin Care just sued the NHS for a fortune. 1 Dec 2017. www.keithtaylormep. org.uk/2017/12/01/virgin-care-just-sued-the-nhs-for-a-fortune-and-the-tories-and-lib-demsmade-it-possible/.

3 BMA. State of the health system—beds in the NHS: Scotland. Feb 2017. http://bit.ly/ 2EkyVjA.

4 King's Fund. NHS hospital bed numbers: past, present, future. 29 Sept 2017. https://www. kingsfund.org.uk/publications/nhs-hospital-bed-numbers.

5 McCartney M. PricewaterhouseCoopers report on technology was expensive and is flawed. 3 April 2013. http://margaretmccartney.com/2013/04/03/price-waterhouse-coopersreport-on-technology-was-expensive-and-is-flawed/.
} 
6 Department of Health, Burstow P. Telehealth and Telecare could save NHS £1.2 billion. 7 March 2012. https://www.gov.uk/government/news/telehealth-and-telecare-could-savenhs-1-2-billion.

7 HendersonCKnappMFernándezJ-LWhole System Demonstrator evaluation team. Cost effectiveness of telehealth for patients with long term conditions (Whole Systems Demonstrator telehealth questionnaire study): nested economic evaluation in a pragmatic, cluster randomised controlled trial. BMJ2013;346:f1035. doi:10.1136/bmj.f103523520339

8 Institute for Fiscal Studies. National standards, local risks: the geography of local authority funded social care 2009-10 to 2015-16. 5 April 2017. https://www.ifs.org.uk/publications/ 9122
9 Mind. Judicial review—FAQs. https://www.mind.org.uk/media/1957492/judicial-reviewfaqs.pdf.

10 BarrBTaylor-RobinsonDStucklerDLoopstraRReevesAWhiteheadM. 'First, do no harm': are disability assessments associated with adverse trends in mental health? A longitudinal ecological study. J Epidemiol Community Health2016;70:339-45.

doi:10.1136/jech-2015-20620926573235

Published by the BMJ Publishing Group Limited. For permission to use (where not already granted under a licence) please go to http://group.bmj.com/group/rights-licensing/ permissions 